\title{
International variation in radiation dose for computed tomography examinations: prospective cohort study
}

\author{
Rebecca Smith-Bindman, ${ }^{1}$ Yifei Wang, ${ }^{2}$ Philip Chu, ${ }^{2}$ Robert Chung, ${ }^{3}$ Andrew J Einstein, ${ }^{4}$ \\ Jonathan Balcombe, ${ }^{5}$ Mary Cocker, ${ }^{6}$ Marcos Das, ${ }^{7,8}$ Bradley N Delman, ${ }^{9}$ Michael Flynn, ${ }^{10}$ \\ Robert Gould, ${ }^{2}$ Ryan K Lee, ${ }^{11}$ Thomas R Nelson, ${ }^{12}$ Sebastian Schindera, ${ }^{13}$ \\ Anthony Seibert, ${ }^{14}$ Jay Starkey, ${ }^{15}$ Saravanabavaan Suntharalingam, ${ }^{16}$ Axel Wetter, ${ }^{17}$ \\ Joachim E Wildberger, ${ }^{8}$ Diana L Miglioretti ${ }^{18,19}$
}

For numbered affiliations see end of article.

Correspondence to:

R Smith-Bindman, School of Medicine, 350 Parnassus

Avenue, San Francisco CA

94117, USA; Rebecca.SmithBindman@ucsf.edu

Additional material is published online only. To view please visit the journal online.

Cite this as: BMJ 2019;364:k4931 http://dx.doi.org/10.1136/bmj.k4931

Accepted: 30 October 2018

\begin{abstract}
OBJECTIVE

To determine patient, institution, and machine characteristics that contribute to variation in radiation doses used for computed tomography (CT).

DESIGN

Prospective cohort study.

SETTING

Data were assembled and analyzed from the University of California San Francisco CT International Dose Registry.

\section{PARTICIPANTS}

Standardized data from over 2.0 million CT examinations of adults who underwent $\mathrm{CT}$ between November 2015 and August 2017 from 151 institutions, across seven countries.

\section{MAIN OUTCOME MEASURES}

Mean effective doses and proportions of high dose examinations for abdomen, chest, combined chest and abdomen, and head CT were determined by patient characteristics (sex, age, and size), type of institution (trauma center, care provision 24 hours per day and seven days per week, academic, private), institutional practice volume, machine factors (manufacturer, model), country, and how scanners
\end{abstract}

\section{WHAT IS ALREADY KNOWN ON THIS TOPIC}

Radiation doses used for computed tomography (CT) are highly variable across patients, institutions, and countries

Lowering patients' exposure to radiation, a known carcinogen, requires an understanding of factors contributing to this variation

Owing to differences in patient populations and inconsistencies in data collection and analysis, accurately quantifying the dose variation or determining whether differences are primarily driven by specific factors has been difficult

\section{WHAT THIS STUDY ADDS}

Variation in doses used for CT scanning across patients is primarily driven by how CT scanners are used, and not to factors related to the patient, institution, or machine

The large variation in doses across countries is mainly attributable to institutional decisions regarding the technical parameters that are used rather than to underlying differences in the patients scanned or the machines used

These findings suggest that optimizing doses to a consistent standard is possible, which will probably require more education of individuals who create protocols for $\mathrm{CT}$, recalibration of image quality expectations targeted to answering the clinical question at hand, and greater sharing of protocols across institutions were used, before and after adjustment for patient characteristics, using hierarchical linear and logistic regression. High dose examinations were defined as CT scans with doses above the 75 th percentile defined during a baseline period.

\section{RESULTS}

The mean effective dose and proportion of high dose examinations varied substantially across institutions. The doses varied modestly (10-30\%) by type of institution and machine characteristics after adjusting for patient characteristics. By contrast, even after adjusting for patient characteristics, wide variations in radiation doses across countries persisted, with a fourfold range in mean effective dose for abdomen CT examinations (7.0-25.7 mSv) and a 17-fold range in proportion of high dose examinations (4-69\%). Similar variation across countries was observed for chest (mean effective dose 1.7-6.4 mSv, proportion of high dose examinations 1-26\%) and combined chest and abdomen CT (10.0-37.9 mSv, 2-78\%). Doses for head CT varied less (1.4-1.9 mSv, 8-27\%). In multivariable models, the dose variation across countries was primarily attributable to institutional decisions regarding technical parameters (that is, how the scanners were used).

\section{CONCLUSIONS}

CT protocols and radiation doses vary greatly across countries and are primarily attributable to local choices regarding technical parameters, rather than patient, institution, or machine characteristics. These findings suggest that the optimization of doses to a consistent standard should be possible.

STUDY REGISTRATION

Clinicaltrials.gov NCT03000751.

\section{Introduction}

Radiation doses for computed tomography (CT) vary substantially across patients, institutions, and countries. ${ }^{1-4}$ Ionizing radiation is a known carcinogen, ${ }^{5-10}$ and CT radiation is associated with increased cancer incidence. ${ }^{11-14}$ Therefore, it is important to minimize exposure from medical imaging and reduce unnecessary variation by optimizing examination protocols. Evidence suggests that in many instances, CT doses can be reduced by $50 \%$ or more without reducing diagnostic accuracy. ${ }^{15}$ However, differences in patient populations and inconsistencies in data collection and analysis have challenged both accurate quantification of dose variations and 
determination if variability is driven primarily by patient characteristics (patient size, indications for imaging), institution type (eg, academic, private, trauma facility, or $24 \mathrm{~h}$ /day provider of CT), machine factors (eg, machine age, specific manufacturer and model, or use of updated software that permits dose reduction), or regional choices that affect dose optimization or image quality (or both). For example, the European Union collects dose levels in Europe, but differences in definitions and data collection techniques across member states confound the identification of factors that explain the observed variation. ${ }^{3}$ To develop optimization activities likely to meaningfully affect CT doses, we must understand the factors that influence them.

Various approaches have been used to optimize CT radiation doses. For example, doses for individual patients can be minimized by refining the scan coverage, altering technical parameters (eg, the machine's $\mathrm{x}$ ray tube current) or by techniques such as iterative reconstruction. ${ }^{16}$ One widely used approach to standardize radiation doses is the creation of target dose levels ${ }^{17}$ or diagnostic reference levels. Levels are defined for groups of patients receiving broadly defined study types with the expectation that under best practices, levels will not be exceeded for average sized patients. ${ }^{3}$ Levels are frequently the 75 th percentile of the observed dose distribution for a geographical area. ${ }^{31819}$ Target doses and diagnostic reference levels are often set locally, on the assumption that dose variation is driven by differences in equipment or patients. ${ }^{20} 21$ However, without understanding precise factors behind variation in reported doses, it is unknown whether the setting of target levels locally is needed. For example, if dose variations between localities reflect differences in how CT machines are used rather than differences in underlying patient populations or machine manufacturer or specific models, setting standards and targets locally needlessly complicates optimization activities.

The University of California San Francisco CT International Dose Registry collects data from participating healthcare institutions worldwide that perform CT. In this study, we sought to use registry data to understand factors that influence CT dose, to inform development of dose optimization approaches, and to ultimately investigate the need (or lack of) to localize target levels.

\section{Methods}

Registry

The University of California San Francisco CT International Dose Registry was created to pool CT dose data from collaborating institutions on $100 \%$ of CT scans performed. Radiation and imaging data stored in digital imaging and communications in medicine (DICOM) format are exported onto a local server directly from the CT machines or via the picture archiving and communication systems (PACS) used to review these examinations. Data are stripped of patient identifying information other than study date and time, and transferred to the dose registry in real time.

\section{Collaborating institutions}

All healthcare institutions that used Radimetrics software (Bayer) in 2015 to monitor medical imaging radiation dose were invited by email to participate in the registry. The registry is a convenience sample and includes data from sites that expressed interest in participating and who were able to complete the logistical requirements of establishing data connections, complete data use agreements, receive institutional review board approval, and agree to complete the study aims. Institutions from seven countries were included.

\section{Study population}

We included diagnostic CT examinations of the abdomen (including any imaging through the abdomen or pelvis), chest, combined chest and abdomen, and head in adults aged 18 years and older between 1 November 2015 and 22 August 2017. Cardiac exams were excluded. The four groups included anatomical areas reflecting about $92 \%$ of all diagnostic CT exams during the study period. Spine CT, and exams performed across multiple anatomical areas comprised most of the excluded exams. CT exams for research, radiation oncology guidance, surgical or interventional procedures, or that were part of combined positron emission tomography-CT exams or single photon emission tomography-CT exams were excluded because of expected heterogenous doses for these study types.

\section{Variables}

Analyses were at the CT examination level, defined as a complete CT study, which could include several CT scans such as with and without intravenous contrast. Statistical analyses were performed separately for each anatomical area.

The analyses adjusted for a range of variables that we hypothesized might be associated with radiation doses. Patient characteristics extracted for each examination were age, sex, and size. Sex and size might be factors because the larger a patient, the greater the doses of radiation that must be used to generate an image equal in quality compared with doses needed in a smaller patient. Patient diameter, the proxy for size, was calculated as the average of the water equivalent diameter from each CT acquisition over the entire imaging range. ${ }^{22}$ Age could be important because institutions might lower doses for younger patients. Scanning indication could influence the radiation doses needed, because greater imaging quality might be needed for particular clinical questions, but was known for only a subset of examinations and could not be used to adjust for possible case mix differences across institutions. Instead, differences in dose were assessed by examination time of day, because those taking place at night (between $10 \mathrm{pm}$ and $5 \mathrm{am}$ ) should primarily reflect acute imaging. 
The type of institution might reflect the types and complexity of the patients seen at that institution, and therefore could predict doses use for imaging. The type of institution was extracted from a survey completed by each institution, which also included trauma center status, whether imaging was provided $24 \mathrm{~h} /$ day and 7 days/week (24/7), and self identification as an academic or private institution. Average machine and institutional practice volumes could be associated with dose based on volume-outcome associations described in many other areas of medical practice. Volumes were calculated on the basis of all CT examinations performed on weekdays.

Machine characteristics included manufacturer and model. These factors could be associated with dose because the technical capacity of machines have changed over time. Further, newer machines sometimes offer dose reduction software.

The technical parameters ${ }^{23}$ (including $\mathrm{x}$ ray tube parameters ( $\mathrm{kV}$ and $\mathrm{mAs}$ ), acquisition parameters (pitch and acquired slice thickness), scan length, and number of scans per examination) and CT dose metric parameters (volumetric CT dose index and dose length product) were stored for each CT scan. The volumetric CT dose index reflects the average dose value within a section (slice) of the scanned volume, whereas the dose length product reflects the total emitted radiation imparted to the patient (defined as volumetric CT dose index $\times$ scan length). Effective dose, which is proportional to total imparted radiation, is an estimate that accounts for estimated future cancer risk based on irradiated organs. If multiple CT scans were performed during an examination, a weighted average of the technical parameters was used. The number of CT scans did not include localizers or contrast bolus timing scans, although the radiation from the contrast bolus was included in the dose calculations. Effective dose was calculated for each examination by use of the dose length product and published conversion factors. $^{22}$

\section{Statistical analysis}

We calculated descriptive statistics for CT scans by patient, institution, practice volume, machine, and country. The dose metrics of interest were effective dose (mean, standard deviation, median, and interquartile range) and the prevalence of high dose studies, defined as studies whose effective dose exceeded the 75 th percentile during the first six months of study (1 November 2015 to 30 April 2016). Variation by less than $50 \%$ was considered modest variation.

Variation in radiation doses across institutions and countries and by predictive variables

We calculated the distribution in radiation doses for abdominal CT by institution and for all anatomical areas by country after adjusting for patient characteristics. The mean effective dose (and standard deviation) and proportion of high dose studies by institution, practice volumes, machine, and country are shown unadjusted and adjusted for patient characteristics to show how the doses vary by these factors. The adjusted effective dose and adjusted prevalence of high dose examinations were estimated by log-linear regression and logistic regression, respectively.

\section{Multivariate analysis to identify factors that are associated with dose}

To understand the contribution of patient, institution, practice volume, machine, country, and technical factors to the variation of effective dose between machines and countries, we fit a series of log-linear mixed effects models predicting effective dose. We graphically show a series of models displaying how the doses vary across the 290 machines included in the University of California San Francisco CT International Dose Registry. The first model contained no predictors except for a random effect accounting for clustering by machine and showed the average dose for each machine for abdomen CT. The second model added patient characteristics, showing the average dose for each machine after accounting for patient characteristics. Additional predictors were subsequently added to each model so that the final fully adjusted model included all of the predictor variables and log-transformed technical parameters (kVp, mAs, pitch, number of CT scans, scan length, and slice thickness).

To quantify variation in dose across the different machines and the reduction in variation after accounting for each predictor variable, we randomly sampled random effects for 10000 pairs of machines from the estimated distribution and computed the ratio of the estimates for each pair. We presented the median, 75th percentile, and 95th percentile of these 10000 bootstrapped ratios as relative doses. The 95\% in the relative dose was used to quantify the variation between two randomly selected machines. The larger the ratio between two randomly selected machines, the greater the variation in dose across machines in the registry. A sharp decline in the variability of relative dose among machines and countries after a predictor was added indicates that the predictor accounted for a large amount of the variation. We also computed the expected mean effective dose in each country for each model, also shown in the figures.

The magnitude of the associations between dose and patient, institution, practice volume, machine, and country are also shown. The effect sizes were defined as the multiplicative change in dose for each standard deviation change in the associated covariate; the larger the estimated effect, the more important the variable. Lastly, we showed the effect of the inclusion of technical factors on the observed variation in dose across countries.

\section{Sensitivity analysis}

To remove the potential effect of case mix (that is, different reasons why patients underwent CT), we illustrated the variation in effectivedoses for one specific imaging indication: suspected pulmonary embolism. We also did a subanalysis for this indication using 
data from one machine model (Somaton Definition AS, Siemens Healthineers) to illustrate representative differences in technical parameters chosen by institutions for this indication and on this scanner. The main analyses were repeated using volumetric CT dose index as the outcome, and restricting to single phase CT examinations. We compared doses in the registry to published benchmarks, extracting combined data across age, sex, and size categories. ${ }^{3} 424-28$ We abstracted effective doses from published reports, or calculated these from dose length product values using published conversion factors. $^{22}$

\section{Patient and public involvement}

Patients were included as stakeholders in the project and contributed as part of in-person meetings and webinars to help guide the project direction.

\section{Results}

During the study period, 151 institutions from seven countries (Switzerland, Netherlands, Germany, United Kingdom, United States, Israel, and Japan) performed just over 2.0 million CT scans on about 1.7 million adults. Examinations were performed on 290 machines from four machine manufacturers and 49 machine models (table 1). Of the included CT scans, about one third were abdomen ( $n=724627,36 \%)$, one third head $(682701,34 \%)$, and one third chest $(\mathrm{n}=515007,26 \%)$ or combined chest and abdomen ( $n=83124,4 \%)$. Numbers of examinations by patient, institution, practice volumes, machine, and country are shown in table 1.

\section{Factors associated with CT dose}

After accounting for patient characteristics, the median effective doses for abdominal CT across institutions ranged from 5 to $32 \mathrm{mSv}$ (fig 1). The distribution in effective dose by country for each anatomical area (fig 2) demonstrated the greatest variation in median doses for abdomen and combined chest and abdomen CT.

The mean effective dose and proportion of high dose examinations by institution, practice volume, machine, and country after adjustment for patient characteristics are shown in table 2 (corresponding unadjusted values in table S1). The adjusted mean effective doses varied modestly (typically by $10-20 \%$; occasionally by up to $40 \%$ ) by institutional characteristics and practice volumes. For example, mean effective dose for abdomen CTs was $12.1 \mathrm{mSv}$ at trauma centers compared with $12.5 \mathrm{mSv}$ at a non-trauma center (relative dose $0.97 \mathrm{mSv}$ ). The adjusted mean effective dose also varied modestly by manufacturer. In contrast with other factors considered, mean doses varied widely across countries, particularly for abdomen, chest, and combined chest and abdomen CT. Mean effective dose for abdomen CT ranged fourfold across countries $(7.0 \mathrm{mSv}$ in the Netherlands to $25.7 \mathrm{mSv}$ in Japan), and the relative proportion of high dose studies varied more than 17-fold (4-69\%). Variation was similar for effective dose for chest and combined chest and abdomen CT, with fourfold differences in mean dose across countries. Dose variation in head CT was more modest, with a relative mean dose between the highest dose and lowest dose countries of 1.3 (range 1.4-1.9 mSv).

In the subanalysis of patients who underwent CT for suspected pulmonary embolism scans, the variation in effective dose was substantial across countries (table 2). Mean effective dose ranged from $2.2 \mathrm{mSv}$ to 33.2 $\mathrm{mSv}$, and the relative proportion of high dose studies ranged from $0 \%$ to $89 \%$ (table 2). Variation in doses across countries were generally greater, rather than reduced, after adjustment for patient factors (table $2 v$ table S1).

\section{Factors explaining CT dose variation}

The multivariable analyses highlighted that most factors considered (patient, practice volumes, machine factors) had only a small effect on the dose variation across different machines in the registry or between the different countries (fig 3, figures S1a-d). For abdomen CT examinations, the unadjusted 95th percentile of relative dose was 2.65 , and the mean effective dose ranged from $7.3 \mathrm{mSv}$ in Switzerland and Germany to $15.7 \mathrm{mSv}$ in Israel, reflecting large variation between machines and countries. Subsequent adjustment for patient factors had no effect on relative dose (2.65) and resulted in a small increase (rather than decrease) in the differences in mean dose by country (range of 8.1 to $22.9 \mathrm{mSv}$ ). This suggests that despite the effective dose being highly correlated with patient characteristics (specifically patient size; table $\mathrm{S} 1$, table 3 ), patient size does little to explain the variability across machines or countries (fig 3, model 2). Sequential adjustment for institution and machine characteristics also had little effect on relative dose, although these adjustments slightly attenuated dose variation across countries (fig 3, models 3-5).

The final adjustment including the specific technical factors substantially reduced or eliminated large differences in relative dose between machines and reduced or eliminated the large differences across countries. In model 6 (fig 3), the technical factors explained nearly all dose variation (95th percentile relative dose 1.42), and average doses among countries were similar after this final adjustment. Results were similar for the chest, combined chest and abdomen, and the subanalysis for pulmonary embolisms (figures $\mathrm{S} 1 \mathrm{a}, \mathrm{b}$, and d). We saw large differences in the relative doses across machines and countries that were reduced or eliminated only after inclusion of the technical parameters. We found less variation in doses for head CT even without adjustment (figures S1c).

\section{Effect of each predictive factor in multivariable models}

Table 3 shows the magnitude of the association between effective dose and patient, institution, practice volume, machine, and country characteristics, based on the multivariate results. Patient size was a significant predictor of mean dose in the fully adjusted multivariable models with large effect sizes; for each 


\begin{tabular}{|c|c|c|c|}
\hline & CT examinations $(n=2005459)$ & Institutions $(\mathrm{n}=151)$ & Machines $(n=290)$ \\
\hline \multicolumn{4}{|l|}{ Anatomical area } \\
\hline Abdomen & $724627(36)$ & - & - \\
\hline Chest & $515007(26)$ & - & - \\
\hline Combined abdomen and chest & $83124(4)$ & - & - \\
\hline Head & $682701(34)$ & - & - \\
\hline \multicolumn{4}{|l|}{ Patient characteristics } \\
\hline \multicolumn{4}{|l|}{ Age (years) } \\
\hline $18-29$ & $179889(9)$ & - & - \\
\hline $30-39$ & $177964(9)$ & - & - \\
\hline $40-49$ & $251366(13)$ & - & - \\
\hline $50-59$ & $385556(19)$ & - & - \\
\hline $60-69$ & $439115(22)$ & - & - \\
\hline $70-79$ & $337904(17)$ & - & - \\
\hline$\geq 80$ & $233665(12)$ & - & - \\
\hline \multicolumn{4}{|l|}{ Sex } \\
\hline Female & $1056929(53)$ & - & - \\
\hline Male & $948530(47)$ & - & - \\
\hline \multicolumn{4}{|l|}{ Size $^{*}$} \\
\hline Smallest & $369967(20)$ & - & - \\
\hline Small & $369938(20)$ & - & - \\
\hline Medium & $369939(20)$ & - & - \\
\hline Large & $369925(20)$ & - & - \\
\hline Largest & $369934(20)$ & - & - \\
\hline \multicolumn{4}{|l|}{ Time of scanning } \\
\hline Daytime & $1783910(89)$ & - & - \\
\hline Night time & $221549(11)$ & - & - \\
\hline \multicolumn{4}{|l|}{ Institutional characteristicst } \\
\hline Trauma center & $790912(39)$ & $25(17)$ & - \\
\hline Institution scans $24 / 7$ & $1605234(80)$ & $64(42)$ & - \\
\hline Academic & $967012(48)$ & $41(27)$ & - \\
\hline Private & $204962(10)$ & $12(8)$ & - \\
\hline \multicolumn{4}{|l|}{ Machine daily volume } \\
\hline $1-6$ & $112847(6)$ & - & $98(34)$ \\
\hline$>6-9$ & $108127(5)$ & - & $33(11)$ \\
\hline$>9-12$ & $157327(8)$ & - & $34(12)$ \\
\hline$>12-20$ & $583851(29)$ & - & $71(24)$ \\
\hline$>20-60$ & $1043307(52)$ & - & $54(19)$ \\
\hline \multicolumn{4}{|l|}{ Facility daily volume } \\
\hline $1-6$ & $77001(4)$ & $58(38)$ & - \\
\hline$>6-9$ & $40386(2)$ & $13(9)$ & - \\
\hline$>9-20$ & $113142(6)$ & $20(13)$ & - \\
\hline$>20-50$ & $583408(29)$ & $32(21)$ & - \\
\hline$>50-600$ & $1191522(59)$ & $28(19)$ & - \\
\hline \multicolumn{4}{|l|}{ Manufacturer $¥$} \\
\hline GE & 873965 (44) & $92(61)$ & $147(51)$ \\
\hline Philips & 381917 (19) & $28(19)$ & $44(15)$ \\
\hline Siemens & $552222(28)$ & $43(28)$ & $78(27)$ \\
\hline Toshiba & $197355(10)$ & $16(11)$ & $21(7)$ \\
\hline \multicolumn{4}{|l|}{ Country } \\
\hline Switzerland & $37119(2)$ & $2(1)$ & $4(1)$ \\
\hline Netherlands & $38034(2)$ & $1(1)$ & $5(2)$ \\
\hline Germany & $45599(2)$ & $4(3)$ & $7(2)$ \\
\hline UK & $61888(3)$ & $3(2)$ & $9(3)$ \\
\hline USA & $1627834(81)$ & $133(88)$ & $253(87)$ \\
\hline Israel & $133031(7)$ & $5(3)$ & $5(2)$ \\
\hline Japan & 61954 (3) & $3(2)$ & $7(2)$ \\
\hline \multicolumn{4}{|c|}{ 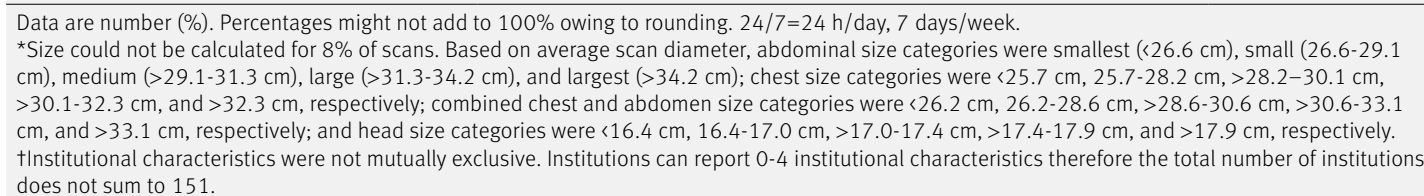 } \\
\hline
\end{tabular}

standard deviation increase in patient size, mean dose increased by $36-47 \%$ for chest, abdomen, and combined chest and abdomen CT, and increased by
$19 \%$ for head CT. We saw only small differences in dose by institutional characteristics; mean doses were slightly but significantly higher for chest and head CT 


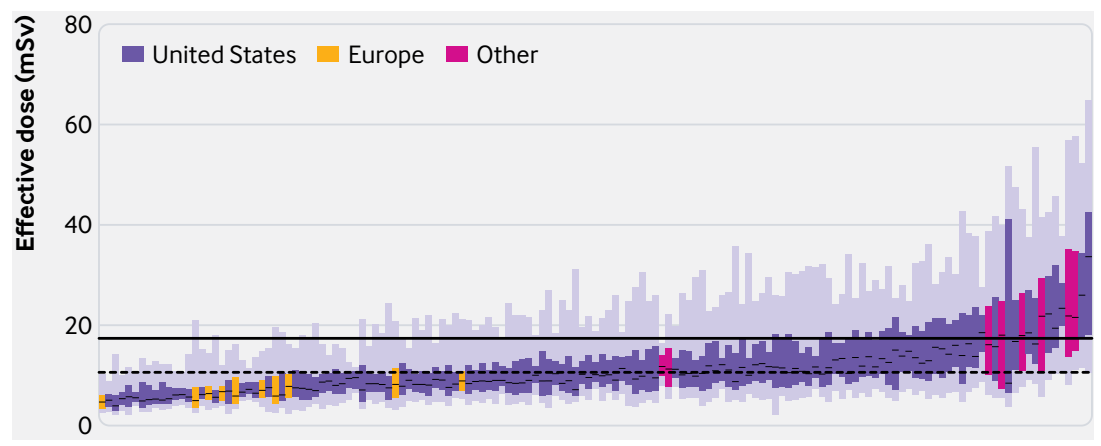

Fig 1 | Distribution in effective radiation dose by institution for abdomen CT, after adjustment for patient characteristics. Each column signifies one institution, ranked by mean effective dose. Light purple columns $=5$ th and 95 th percentiles of effective dose; dark purple, pink, and yellow column sections $=25$ th and 75 th percentiles of effective dose; lines=medians; horizontal solid line and dashed line=benchmark and target doses for abdomen, defined as the 75th and 50th percentiles of dose for all abdominal scans performed before 30 April 2016

at trauma centers, and head CT doses were higher at private institutions and those with scanning provided $24 \mathrm{~h} /$ day and 7 days/week. Most other institutional characteristics were not significantly associated with mean dose.

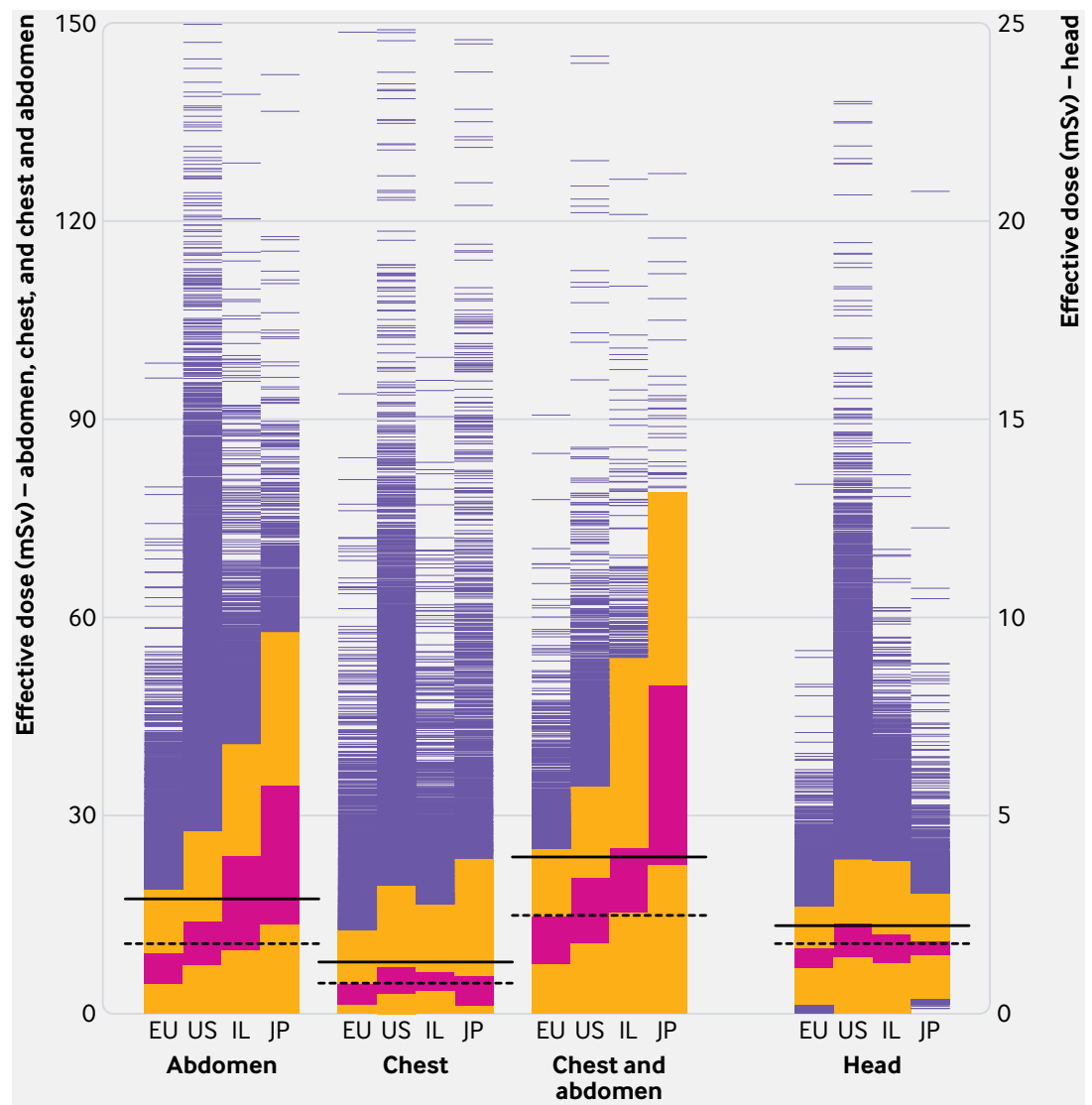

Fig 2 | Distribution of effective radiation dose by country and scan region, after adjustment for patient characteristics. Each column signifies one country or the European Union, with one horizontal line denoting each observation within the country. $\mathrm{IL}=$ Israel; JP= Japan; pink lines=within 25 th and 75th percentiles; orange lines=two standard deviations from the mean; purple lines=outliers; horizontal solid line and dashed line=benchmark and target doses for each anatomical area, defined as the 75th and 50th percentiles of dose for all scans of that type performed before 30 April 2016
Abdomen, chest, and combined chest and abdomen CT doses did not differ significantly by manufacturer, although machines from Canon Medical Systems (Toshiba) were associated with modestly increased doses for head scans and machines from Siemens were associated with modestly reduced doses for suspected pulmonary embolism scans.

Although most predictive factors had relatively small effects on dose, large differences in dose persisted among countries for abdomen, chest, and combined chest and abdomen CT and for pulmonary embolism CT. The differences among countries was largest for suspected pulmonary embolism CT. We saw no significant differences in mean effective dose by country for head CT after accounting for other factors, suggesting a greater degree of protocol standardization for head imaging. The addition of specific scan parameters to the multivariable models (eg, $\mathrm{x}$ ray tube and acquisition parameters; table 4) attenuated or eliminated the differences between countries. This suggests that the differences among countries in the mean doses were not attributable to patient, institution, or machine factors (which all had small effects in table 3), but to the technical parameters.

\section{Effect of technical parameters on CT dose for one} indication

Subanalysis of one specific indication (suspected pulmonary embolism) highlighted differences in technical parameters chosen by different institutions using the same machine make and model that resulted in the large observed differences in effective dose (table 5 ). We found a greater than 15 -fold difference in mean effective doses between the institutions with the highest tenth versus lowest tenth in dose (mean effective dose $31.0 v 2.0 \mathrm{mSv}$ ). Accounting for patient size resulted in a slightly greater difference between the highest tenth and lowest tenth in protocols (mean effective dose 27.5 $v 1.6 \mathrm{mSv}$ ). Compared with institutions in the highest tenth of effective dose, those in the lowest tenth had a lower adjusted CT dose index (3.8 v $15.9 \mathrm{mGy})$, tube potential (102 v $119 \mathrm{kVp})$, tube current (113 $v 188$ mAs), slice thickness $(1.9 v 3.9)$, number of CT scans per examination ( $1.0 v 2.7)$, and had higher pitch (1.2v 0.8 ). Thus, as shown for the analyses at the anatomical area level, dose variations in pulmonary embolisms CT, even when restricted to the same machine model, were explained by differences in technical parameters rather than patient characteristics.

\section{Sensitivity analyses}

Results were similar when we used the volumetric CT dose index as the outcome dose metric (results not shown), and when limited to single CT scan examinations (results not shown). The unadjusted doses in the University of California San Francisco CT International Dose Registry were similar to data in the literature (table S2). For example, the published benchmark abdomen dose in Switzerland is $10 \mathrm{mSv}$, and is $10.3 \mathrm{mSv}$ (95\% confidence interval 9.9 to 10.6) in the University of California San Francisco registry. 


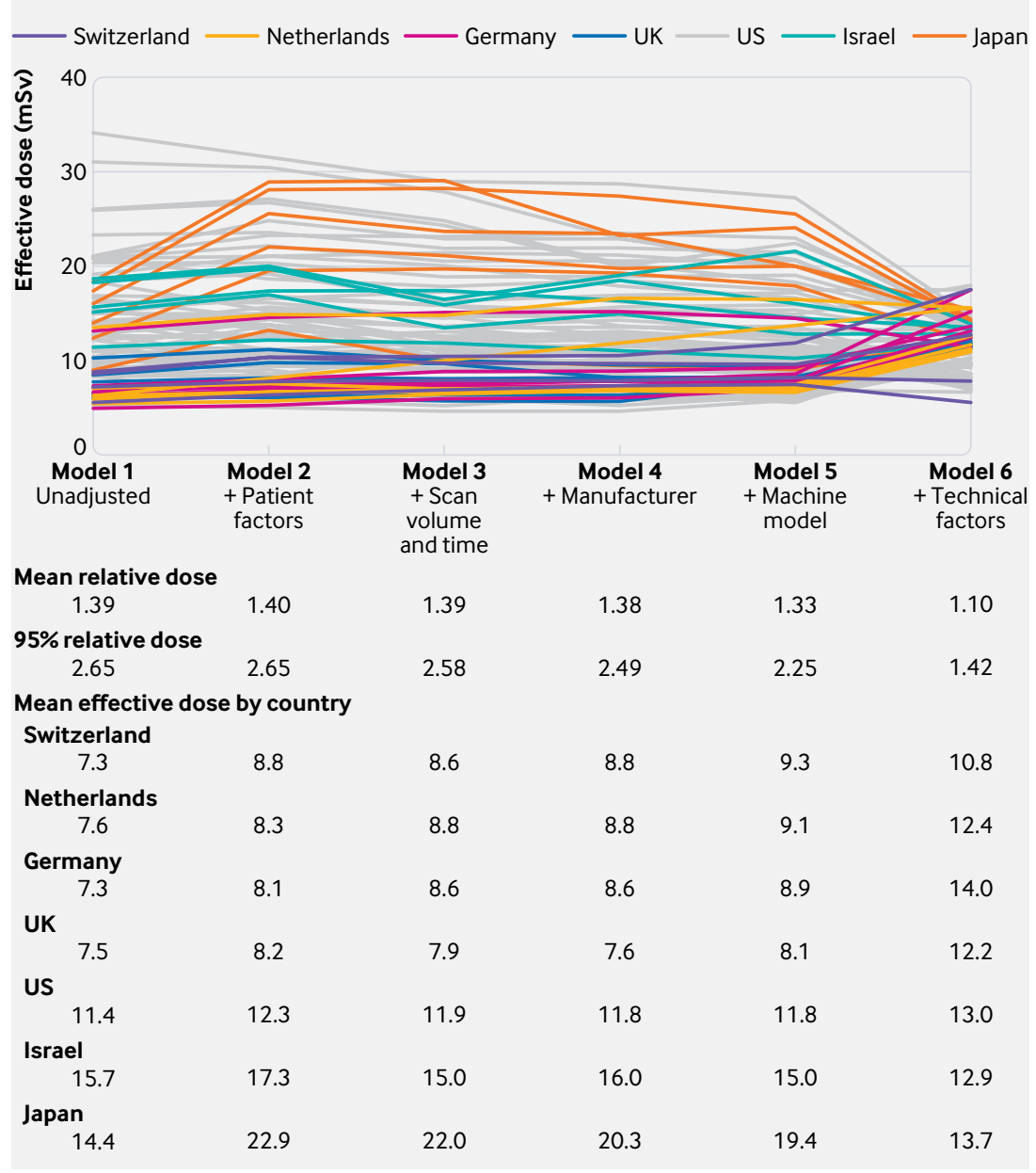

Fig 3 | Mean effective radiation dose by machine in abdomen computed tomography (CT) scans, with different levels of adjustment. Model 1=unadjusted results; subsequent adjustments included: model 2, patient characteristics; model 3, institutional characteristics; model 4, machine manufacturer; model 5, machine model; and model 6, technical parameters. Rows=mean relative effective dose and 95th percentile of relative dose for two randomly chosen machines, with mean dose by country at the corresponding level of adjustment within multivariable model. Lines=dose for single machines. For abdomen examinations in model 1 , 95th percentile of relative dose was 2.65 and mean effective dose ranged from $7.3 \mathrm{mSv}$ (Switzerland) to $15.7 \mathrm{mSv}$ (Israel) among countries were not attributable to patient or institutional characteristics or machine manufacturer or model, but were almost entirely associated with how institutions used the machines, presumably reflecting different decisions about technical parameters to yield optimal CT images.

\section{Comparison with other studies}

International efforts to improve radiation safety for medical imaging vary considerably across the included countries, so it is not surprising that we found CT dose differences. $^{3} 2429$ 30-36 For example, the EU adopted legislation with mandatory directives about medical radiation exposure from CT where member states are required to establish and promote diagnostic reference levels for CT. ${ }^{31-34}$ The US has educational efforts by professional societies, such as the American College of Radiology, ${ }^{29}$ and recommendations from government agencies ask institutions to assess their CT doses. ${ }^{37}$ However, no US organization is tasked with collecting, monitoring, or reporting CT radiation doses, and no national US legislation sets CT dose standards. ${ }^{38}$ Only two US states (California and Texas) have legislation related to CT scanning. In Japan, a consortium group has proposed national diagnostic reference levels, but these have not been widely adopted. ${ }^{24}$ In Israel, a few institutions have established diagnostic reference levels, but adoption is not uniform, although currently the ministry of health is considering establishment of a national dose registry.

One approach to optimizing CT doses has been setting benchmarks for optimum target doses. Challenges in setting benchmarks include difficulty in deciding how they should be established-for example, by anatomical area, clinical indication, or protocol $^{3242529}$-and difficulty in collecting sufficient data to reflect actual practice. The ideal approach to creating benchmarks would likely reflect a compromise, with target dose levels based on broad anatomical areas, supplemented by additional target dose levels for specific clinical indications that have unique contrast and spatial resolution needs not captured by these broad anatomic areas. ${ }^{39}$

Our analysis used broad anatomical areas and considered the entire CT examination for several reasons. Firstly, having fewer categories simplified comparisons across institutions. Secondly, institutional decisions to use particular approaches (eg, single or multiple CT scan examinations) affects the doses delivered, and to stratify results within these narrow categories would mask the primary contributor to dose variation. For example, if an institution routinely uses multiple CT scan examinations to assess pulmonary embolism, this will result in higher radiation doses to their patients compared with facilities that routinely use just one CT scan examination. Assessment of doses within narrowly defined categories of single or multiple phase would mask differences and would not enable identification of institutions whose doses are outside practice norms because they use multiple scan examinations. Furthermore, there are few evidence 


\begin{tabular}{|c|c|c|c|c|c|c|c|c|c|c|}
\hline & \multicolumn{10}{|c|}{ Effective dose in CT scan (mSv), by anatomical area } \\
\hline & \multicolumn{2}{|l|}{ Abdomen } & \multicolumn{2}{|l|}{ Chest } & \multicolumn{2}{|c|}{$\begin{array}{l}\text { Combined chest and } \\
\text { abdomen }\end{array}$} & \multicolumn{2}{|l|}{ Head } & \multicolumn{2}{|c|}{$\begin{array}{l}\text { Suspected pulmonary } \\
\text { embolism }\end{array}$} \\
\hline & Mean (SD) & $\begin{array}{l}\text { High dose } \\
\text { (\%) }\end{array}$ & Mean (SD) & High dose (\%) & Mean (SD) & $\begin{array}{l}\text { High dose } \\
\text { (\%) }\end{array}$ & Mean (SD) & High dose (\%) & Mean (SD) & High dose (\%) \\
\hline \multicolumn{11}{|c|}{ Institutional characteristics } \\
\hline Trauma center, yes & $12.1(8.6)$ & 22 & $6.9(7.2)$ & 30 & $16.6(10.8)$ & 22 & $2.0(1.0)$ & 27 & $6.6(6.1)$ & 25 \\
\hline Trauma center, no & $12.5(8.7)$ & 25 & $5.4(6.1)$ & 20 & $15.3(8.6)$ & 18 & $1.8(0.9)$ & 22 & $6.4(4.4)$ & 25 \\
\hline Scans $24 / 7$, yes & $11.8(8.3)$ & 20 & $6.3(6.6)$ & 26 & $15.0(10.1)$ & 19 & $1.9(0.9)$ & 25 & $6.3(5.2)$ & 24 \\
\hline Scans 24/7, no & $14.5(9.7)$ & 36 & $5.3(6.3)$ & 17 & $16.7(8.1)$ & 21 & $1.5(1.1)$ & 17 & $8.4(6.1)$ & 40 \\
\hline Academic, yes & $12.2(8.3)$ & 23 & $6.4(7.0)$ & 26 & $16.4(9.1)$ & 21 & $1.9(1.0)$ & 24 & $6.3(4.2)$ & 23 \\
\hline Academic, no & $12.4(8.9)$ & 24 & $5.6(6.1)$ & 21 & $14.5(9.7)$ & 17 & $1.8(0.9)$ & 24 & $6.8(6.4)$ & 27 \\
\hline Private, yes & $16.2(10.2)$ & 42 & $4.6(5.3)$ & 31 & $23.2(14.6)$ & 39 & $1.9(1.0)$ & 21 & $6.5(5.4)$ & 25 \\
\hline Private, no & $11.9(8.3)$ & 21 & $6.2(6.7)$ & 23 & $15.4(9.0)$ & 19 & $1.9(1.0)$ & 25 & $7.0(3.8)$ & 26 \\
\hline \multicolumn{11}{|c|}{ Machine daily volume } \\
\hline $1-6$ & $12.2(8.8)$ & 25 & $5.3(6.8)$ & 17 & $14.0(7.4)$ & 9 & $1.5(1.3)$ & 17 & $6.7(5.3)$ & 27 \\
\hline$>6-9$ & $11.4(7.4)$ & 22 & $5.2(4.8)$ & 21 & $13.6(9.3)$ & 13 & $1.9(1.0)$ & 27 & $7.1(4.7)$ & 37 \\
\hline$>9-12$ & $11.3(7.9)$ & 21 & $6.7(8.5)$ & 23 & $14.6(8.3)$ & 17 & $1.8(0.8)$ & 17 & $6.3(4.6)$ & 20 \\
\hline$>12-20$ & $13.0(9.0)$ & 28 & $5.9(7.1)$ & 24 & $15.0(9.4)$ & 16 & $1.9(0.9)$ & 23 & $7.3(7.1)$ & 30 \\
\hline$>20-60$ & $12.2(8.7)$ & 22 & $6.1(5.7)$ & 25 & $16.5(9.5)$ & 23 & $1.9(1.0)$ & 26 & $6.1(4.4)$ & 22 \\
\hline \multicolumn{11}{|l|}{ Facility daily volume } \\
\hline $1-6$ & $12.3(8.9)$ & 23 & $6.3(6.7)$ & 26 & $15.9(9.3)$ & 21 & $1.9(1.0)$ & 27 & $6.3(5.6)$ & 23 \\
\hline$>6-9$ & $12.0(8.6)$ & 25 & $5.2(6.6)$ & 17 & $14.1(9.2)$ & 13 & $1.4(1.0)$ & 14 & $7.4(5.8)$ & 30 \\
\hline$>9-20$ & $11.7(8.6)$ & 24 & $4.9(4.9)$ & 20 & $15.8(10.1)$ & 19 & $1.8(1.0)$ & 23 & $6.2(3.9)$ & 27 \\
\hline$>20-50$ & $10.5(8.1)$ & 17 & $6.2(8.6)$ & 19 & $10.3(5.9)$ & 6 & $1.7(1.1)$ & 22 & $5.0(3.7)$ & 12 \\
\hline$>50-600$ & $12.7(8.2)$ & 26 & $5.6(5.9)$ & 21 & $16.0(10.0)$ & 17 & $1.8(0.9)$ & 19 & $7.3(4.8)$ & 32 \\
\hline \multicolumn{11}{|l|}{ Manufacturer } \\
\hline GE & $12.7(8.7)$ & 26 & $5.4(5.5)$ & 19 & $17.0(8.6)$ & 23 & $1.8(1.0)$ & 19 & $7.3(5.1)$ & 31 \\
\hline Philips & $12.1(8.9)$ & 24 & $5.7(5.3)$ & 22 & $14.3(10.3)$ & 16 & $1.9(0.9)$ & 29 & $6.2(4.6)$ & 23 \\
\hline Siemens & $12.1(8.3)$ & 22 & $6.4(7.7)$ & 26 & $12.0(8.3)$ & 11 & $1.7(0.8)$ & 17 & $5.4(4.5)$ & 16 \\
\hline Toshiba & $11.8(9.1)$ & 17 & $8.3(9.0)$ & 42 & $18.5(14.2)$ & 26 & $2.3(1.0)$ & 49 & $7.4(7.4)$ & 33 \\
\hline \multicolumn{11}{|l|}{ Country } \\
\hline Switzerland & $8.3(4.4)$ & 7 & $1.7(1.7)$ & 1 & $13.3(7.3)$ & 11 & $1.5(0.5)$ & 8 & $2.2(1.1)$ & 0 \\
\hline Germany & $8.0(7.1)$ & 9 & $3.4(5.3)$ & 11 & $10.0(8.0)$ & 9 & $1.4(0.7)$ & 8 & $2.4(2.6)$ & 3 \\
\hline Netherlands & $7.0(4.1)$ & 4 & $4.7(5.4)$ & 14 & $11.8(4.1)$ & 2 & $1.4(0.6)$ & 15 & $2.2(1.8)$ & 1 \\
\hline UK & $7.9(6.0)$ & 9 & $4.1(3.3)$ & 10 & $12.5(5.2)$ & 6 & $1.5(0.6)$ & 11 & $5.5(4.1)$ & 19 \\
\hline US & $12.0(7.9)$ & 22 & $6.4(6.6)$ & 26 & $16.7(8.9)$ & 23 & $1.9(1.0)$ & 27 & $6.7(4.7)$ & 27 \\
\hline Israel & $18.4(11.3)$ & 54 & $5.8(5.4)$ & 17 & $23.7(15.1)$ & 39 & $1.8(1.1)$ & 17 & $6.2(5.3)$ & 11 \\
\hline Japan & $25.7(16.1)$ & 69 & $5.0(9.3)$ & 20 & $37.9(20.6)$ & 78 & $1.7(0.7)$ & 11 & $33.2(25.0)$ & 89 \\
\hline
\end{tabular}

$24 / 7=24 \mathrm{~h} /$ day, 7 days/week; $\mathrm{mSv}=$ millisievert; $\mathrm{SD}=$ standard deviation.

based guidelines for choosing different approaches to scanning most clinical indications (that is, little data are available to link dose requirements to specific indications or diagnostic accuracy), and thus the use of broad anatomical areas seems most useful. The primary disadvantage of our approach was that grouping of exams by anatomical area precluded accounting for variation in case mix for the few clinical indications that might have unique spacial resolution needs. Inclusion of institutional characteristics in our analyses probably minimized differences by institutions.

A widely held belief is that CT dose standards and benchmarks must be created individually by each hospital, ${ }^{30}$ region, or country, ${ }^{30}$ a tailored approach necessitated by variation in achievable targets that are largely determined by the specific types and models of CT machines used and characteristics of the local patient populations. ${ }^{20} 21$ In the EU, large differences in doses across included nations have been reported, which has contributed to the widely held belief that country specific benchmarks must be created. ${ }^{3} 40$
We did not find that dose variation is largely attributable to variation in patient requirements, clinical circumstances, or machine factors. We found that variations persist even when we limited analysis to patients assessed for a specific clinical condition, adjusted for patient factors, and restricted analysis to patients scanned on a single instrument model. Machine make and model are only modest predictors of dose and that substantial variance for each device type. The largest driver of dose variation was how providers or clinical staff chose to set the machine technical parameters, not the machine. Our results suggest that dose variation and outlier doses could be diminished without new equipment, which would require the creation of consistent standards, and to create those standards, the collection of standardized data across all countries similar to the data we include.

Our findings suggest that work is needed to understand why doses vary among users. The variation in radiation dose across countries will reflect the variation in image quality, and user's willingness to accept noisier images. We need to determine 


\begin{tabular}{|c|c|c|c|c|c|}
\hline & \multicolumn{5}{|c|}{ Effect size $(95 \% \mathrm{Cl})$, by anatomical area of CT scan } \\
\hline & Abdomen & Chest & Combined chest and abdomen & Head & Suspected pulmonary embolism \\
\hline \multicolumn{6}{|l|}{ Patient characteristics } \\
\hline Age, years (per SD) & $1.01(1.00 \text { to } 1.01)^{\star}$ & $0.98(0.97 \text { to } 0.98)^{\star}$ & $0.95(0.95 \text { to } 0.96)^{*}$ & $1.04(1.03 \text { to } 1.04)^{*}$ & $0.99(0.99 \text { to } 0.99)^{\star}$ \\
\hline Sex (male $v$ female) & $1.04(1.04 \text { to } 1.05)^{\star}$ & $1.13(1.12 \text { to } 1.13)^{\star}$ & $1.06(1.06 \text { to } 1.07)^{\star}$ & $0.96(0.96 \text { to } 0.97)^{\star}$ & $1.09(1.09 \text { to } 1.10)^{\star}$ \\
\hline Size (per SD) & $1.47(1.46 \text { to } 1.47)^{\star}$ & $1.36(1.35 \text { to } 1.36)^{\star}$ & $1.43(1.42 \text { to } 1.43)^{\star}$ & $1.19(1.18 \text { to } 1.19)^{\star}$ & $1.41(1.41 \text { to } 1.42)^{\star}$ \\
\hline Night time scan & $0.98(0.97 \text { to } 0.98)^{\star}$ & $1.06(1.06 \text { to } 1.07)^{\star}$ & $1.06(1.04 \text { to } 1.07)^{\star}$ & $1.04(1.03 \text { to } 1.04)^{\star}$ & $1.02(1.01 \text { to } 1.03)^{\star}$ \\
\hline \multicolumn{6}{|c|}{ Institutional characteristics } \\
\hline Trauma center & 0.99 (0.90 to 1.09$)$ & $1.23(1.07 \text { to } 1.42)^{\star}$ & $1.08(0.93$ to 1.25$)$ & $1.13(1.03 \text { to } 1.25)^{\star}$ & $1.10(0.96$ to 1.26$)$ \\
\hline Institution scans $24 / 7$ & $0.87(0.79 \text { to } 0.96)^{\star}$ & $1.13(0.97$ to 1.32$)$ & $0.97(0.82$ to 1.15$)$ & $1.25(1.13 \text { to } 1.39)^{\star}$ & $0.93(0.80$ to 1.08$)$ \\
\hline Academic & $0.98(0.90$ to 1.07$)$ & $1.10(0.96$ to 1.26$)$ & $1.15(0.98$ to 1.35$)$ & 1.09 (0.99 to 1.2$)$ & $0.99(0.87$ to 1.13$)$ \\
\hline Private & 0.99 (0.81 to 1.21$)$ & 0.77 (0.57 to 1.03$)$ & 1.13 (0.84 to 1.54$)$ & $1.27(1.01 \text { to } 1.59)^{\star}$ & 1.11 (0.79 to 1.54$)$ \\
\hline \multicolumn{6}{|l|}{ Volume } \\
\hline Machine & $0.92(0.87 \text { to } 0.98)^{\star}$ & 1.03 (0.95 to 1.12$)$ & 1.00 (0.93 to 1.09$)$ & $1.04(0.98$ to 1.11$)$ & 0.97 (0.90 to 1.05$)$ \\
\hline Facility & $1.08(1.03 \text { to } 1.13)^{*}$ & 1.36 (0.92 to 1.06$)$ & 0.98 (0.91 to 1.05$)$ & 1.01 (0.97 to 1.06$)$ & 1.05 (0.99 to 1.12$)$ \\
\hline \multicolumn{6}{|l|}{ Manufacturer } \\
\hline GE & Reference & Reference & Reference & Reference & Reference \\
\hline Philips & 0.87 (0.74 to 1.01$)$ & 0.79 (0.61 to 1.03$)$ & 0.85 (0.68 to 1.06$)$ & $1.02(0.86 \text { to } 1.21)^{\star}$ & $0.89(0.71 \text { to } 1.13)^{\star}$ \\
\hline Siemens & $1.05(0.92$ to 1.20$)$ & $0.99(0.79$ to 1.23$)$ & $0.90(0.72$ to 1.12$)$ & $1.08(0.94 \text { to } 1.25)^{\star}$ & $0.75(0.62 \text { to } 0.91)^{\star}$ \\
\hline Toshiba & $1.13(0.92$ to 1.37$)$ & 1.21 (0.88 to 1.67$)$ & $1.15(0.87$ to 1.53$)$ & $1.51(1.22 \text { to } 1.87)^{\star}$ & $1.08(0.82 \text { to } 1.41)^{\star}$ \\
\hline \multicolumn{6}{|l|}{ Country } \\
\hline Germany & Reference & Reference & Reference & Reference & Reference \\
\hline Netherlands & $0.99(0.71 \text { to } 1.39)^{\star}$ & $0.71(0.43 \text { to } 1.19)^{\star}$ & $1.15(0.68 \text { to } 1.95)^{*}$ & 0.96 (0.66 to 1.39$)$ & $1.18(0.69 \text { to } 2.02)^{\star}$ \\
\hline Switzerland & $1.11(0.77 \text { to } 1.61)^{\star}$ & $0.38(0.22 \text { to } 0.67)^{\star}$ & $1.11(0.65 \text { to } 1.91)^{\star}$ & 1.06 (0.71 to 1.58$)$ & $1.07(0.62 \text { to } 1.84)^{\star}$ \\
\hline UK & $0.98(0.72 \text { to } 1.33)^{\star}$ & $0.82(0.52 \text { to } 1.32)^{\star}$ & $1.02(0.62 \text { to } 1.67)^{\star}$ & 1.05 (0.74 to 1.48$)$ & $1.54(0.96 \text { to } 2.45)^{\star}$ \\
\hline USA & $1.48(1.17 \text { to } 1.86)^{*}$ & $1.07(0.75 \text { to } 1.52)^{\star}$ & $1.25(0.81 \text { to } 1.92)^{\star}$ & $1.22(0.93$ to 1.58$)$ & $2.31(1.6 \text { to } 3.33)^{\star}$ \\
\hline Israel & $2.69(1.76 \text { to } 4.11)^{\star}$ & $1.77(0.93 \text { to } 3.37)^{\star}$ & $2.28(1.18 \text { to } 4.41)^{\star}$ & $1.1(0.68$ to 1.75$)$ & $1.86(0.97 \text { to } 3.55)^{\star}$ \\
\hline Japan & $2.73(1.95 \text { to } 3.83)^{\star}$ & $0.92(0.56 \text { to } 1.52)^{\star}$ & $2.83(1.61 \text { to } 5.00)^{\star}$ & 1.18 (0.80 to 1.74$)$ & $6.49(3.72 \text { to } 11.35)^{\star}$ \\
\hline
\end{tabular}

how institutions set up their CT scanning protocols and how to develop consensus about balancing image quality with diagnostic accuracy. Education and collaboration in setting standards could offer the largest effect on optimizing dose. ${ }^{41} 42$ Choosing appropriate CT protocol parameters might be less complex than widely believed. Institutions with lower doses shared scanning approaches. These institutions tended to limit the number of protocols, with each relying on the minimum dose required to answer the clinical question. They used multiple CT scanning infrequently, had lower settings for tube current and tube potential, and used higher pitch for most, if not all, imaging indications. The key to protocol optimization is updating physician awareness and recalibrating expectations about what constitutes a diagnostic CT scan based on better alignment of CT protocol parameter choices with diagnostic image quality requirements.

\section{Strengths and limitations}

The main advantages of our study are its large size and detailed and standardized collection of data that allowed us to determine potential contributors to radiation dose. This study also had several limitations. The number of participating institutions for each country outside the US was limited so our data cannot be considered representative of any country as a whole. However, country specific doses in our registry are similar to those reported elsewhere, ${ }^{32425}$ suggesting our estimates are

\begin{tabular}{|c|c|c|c|c|c|c|c|c|c|c|}
\hline & \multicolumn{10}{|c|}{ Effect size $(95 \% \mathrm{Cl})$, by anatomical area of CT scan (with and without technical factors) } \\
\hline & \multicolumn{2}{|l|}{ Abdomen } & \multicolumn{2}{|l|}{ Chest } & \multicolumn{2}{|c|}{ Combined chest and abdomen } & \multicolumn{2}{|l|}{ Head } & \multicolumn{2}{|c|}{$\begin{array}{l}\text { Suspected pulmonary } \\
\text { embolism }\end{array}$} \\
\hline & Without & With & Without & With & Without & With & Without & With & Without & With \\
\hline Germany & Reference & & Reference & & Reference & & Reference & & Reference & \\
\hline Netherlands & $\begin{array}{l}0.99(0.71 \text { to } \\
1.39)^{\star}\end{array}$ & $\begin{array}{l}0.88(0.74 \text { to } \\
1.04)^{*}\end{array}$ & $\begin{array}{l}0.71(0.43 \text { to } \\
1.19)^{\star}\end{array}$ & $\begin{array}{l}0.91(0.72 \text { to } \\
1.15)^{\star}\end{array}$ & $\begin{array}{l}1.15(0.68 \text { to } \\
1.95)^{\star}\end{array}$ & $\begin{array}{l}1.09(0.87 \text { to } \\
1.36)\end{array}$ & $\begin{array}{l}0.96(0.66 \text { to } \\
1.39)\end{array}$ & $\begin{array}{l}1.10(0.92 \text { to } \\
1.30)^{\star}\end{array}$ & $\begin{array}{l}1.18(0.69 \text { to } \\
2.02)^{\star}\end{array}$ & $\begin{array}{l}1.35(1.01 \text { to } \\
1.81)^{\star}\end{array}$ \\
\hline Switzerland & $\begin{array}{l}1.11(0.77 \text { to } \\
1.61)^{\star}\end{array}$ & $\begin{array}{l}0.64(0.53 \text { to } \\
0.78)^{*}\end{array}$ & $\begin{array}{l}0.38(0.22 \text { to } \\
0.67)^{\star}\end{array}$ & $\begin{array}{l}0.73(0.56 \text { to } \\
0.94)^{*}\end{array}$ & $\begin{array}{l}1.11(0.65 \text { to } \\
1.91)^{\star}\end{array}$ & $\begin{array}{l}0.86(0.68 \text { to } \\
1.09)\end{array}$ & $\begin{array}{l}1.06(0.71 \text { to } \\
1.58)\end{array}$ & $\begin{array}{l}1.03(0.85 \text { to } \\
1.25)^{\star}\end{array}$ & $\begin{array}{l}1.07(0.62 \text { to } \\
1.84)^{*}\end{array}$ & $\begin{array}{l}1.15(0.85 \text { to } \\
1.56)^{\star}\end{array}$ \\
\hline UK & $\begin{array}{l}0.98(0.72 \text { to } \\
1.33)^{\star}\end{array}$ & $\begin{array}{l}0.84(0.71 \text { to } \\
0.99)^{*}\end{array}$ & $\begin{array}{l}0.82(0.52 \text { to } \\
1.32)^{\star}\end{array}$ & $\begin{array}{l}0.91(0.73 \text { to } \\
1.14)^{*}\end{array}$ & $\begin{array}{l}1.02(0.62 \text { to } \\
1.67)^{\star}\end{array}$ & $\begin{array}{l}1.02(0.83 \text { to } \\
1.27)\end{array}$ & $\begin{array}{l}1.05(0.74 \text { to } \\
1.48)\end{array}$ & $\begin{array}{l}1.26(1.06 \text { to } \\
1.49)^{\star}\end{array}$ & $\begin{array}{l}1.54(0.96 \text { to } \\
2.45)^{\star}\end{array}$ & $\begin{array}{l}1.49(1.14 \text { to } \\
1.93)^{\star}\end{array}$ \\
\hline US & $\begin{array}{l}1.48(1.17 \text { to } \\
1.86)^{\star}\end{array}$ & $\begin{array}{l}0.92(0.81 \text { to } \\
1.04)^{\star}\end{array}$ & $\begin{array}{l}1.07(0.75 \text { to } \\
1.52)^{\star}\end{array}$ & $\begin{array}{l}0.92(0.78 \text { to } \\
1.09)^{\star}\end{array}$ & $\begin{array}{l}1.25(0.81 \text { to } \\
1.92)^{\star}\end{array}$ & $\begin{array}{l}1.02(0.85 \text { to } \\
1.23)\end{array}$ & $\begin{array}{l}1.22(0.93 \text { to } \\
1.58)\end{array}$ & $\begin{array}{l}1.08(0.96 \text { to } \\
1.23)^{\star}\end{array}$ & $\begin{array}{l}2.31(1.60 \text { to } \\
3.33)^{\star}\end{array}$ & $\begin{array}{l}1.44(1.18 \text { to } \\
1.76)^{\star}\end{array}$ \\
\hline Israel & $\begin{array}{l}2.69(1.76 \text { to } \\
4.11)^{\star}\end{array}$ & $\begin{array}{l}0.95(0.75 \text { to } \\
1.19)^{\star}\end{array}$ & $\begin{array}{l}1.77(0.93 \text { to } \\
3.37)^{\star}\end{array}$ & $\begin{array}{l}1.00(0.73 \text { to } \\
1.36)^{\star}\end{array}$ & $\begin{array}{l}2.28(1.18 \text { to } \\
4.41)^{\star}\end{array}$ & $\begin{array}{l}1.15(0.87 \text { to } \\
1.54)\end{array}$ & $\begin{array}{l}1.10(0.68 \text { to } \\
1.75)\end{array}$ & $\begin{array}{l}1.17(0.93 \text { to } \\
1.48)^{\star}\end{array}$ & $\begin{array}{l}1.86(0.97 \text { to } \\
3.55)^{\star}\end{array}$ & $\begin{array}{l}1.47(1.02 \text { to } \\
2.11)^{\star}\end{array}$ \\
\hline Japan & $\begin{array}{l}2.73(1.95 \text { to } \\
3.83)^{\star}\end{array}$ & $\begin{array}{l}0.98(0.83 \text { to } \\
1.17)^{*}\end{array}$ & $\begin{array}{l}0.92(0.56 \text { to } \\
1.52)^{*}\end{array}$ & $\begin{array}{l}0.88(0.70 \text { to } \\
1.11)^{*}\end{array}$ & $\begin{array}{l}2.83(1.61 \text { to } \\
5.00)^{\star}\end{array}$ & $\begin{array}{l}1.27(1.00 \text { to } \\
1.63)\end{array}$ & $\begin{array}{l}1.18 \text { (0.8 to } \\
1.74)\end{array}$ & $\begin{array}{l}0.94(0.78 \text { to } \\
1.13)^{\star}\end{array}$ & $\begin{array}{l}6.49(3.72 \text { to } \\
11.35)^{\star}\end{array}$ & $\begin{array}{l}1.70(1.25 \text { to } \\
2.31)^{\star}\end{array}$ \\
\hline
\end{tabular}




\begin{tabular}{|c|c|c|c|c|c|c|c|c|c|c|c|}
\hline Country & $\begin{array}{l}\text { Effective } \\
\text { dose } \\
\text { (mSv) }\end{array}$ & $\begin{array}{l}\text { Adjusted } \\
\text { effective dose } \\
\text { (mSv) }\end{array}$ & $\begin{array}{l}\text { CTDI }_{\text {vol }} \\
(m G y)\end{array}$ & $\begin{array}{l}\text { Adjusted } \\
\text { CTDI } \\
\text { (mGy) }\end{array}$ & $\begin{array}{l}\mathrm{X} \text { ray tube } \\
\text { potential } \\
(\mathrm{kVP})\end{array}$ & $\begin{array}{l}X \text { ray tube } \\
\text { current } \\
\text { (mAs) }\end{array}$ & Collimation & Pitch & $\begin{array}{l}\text { Scan } \\
\text { length } \\
\text { (cm) }\end{array}$ & $\begin{array}{l}\text { Slice } \\
\text { thickness } \\
(\mathrm{mm})\end{array}$ & $\begin{array}{l}\text { No of CT scans } \\
\text { per examination }\end{array}$ \\
\hline Switzerland & $1.9(1.0)$ & $1.7(0.6)$ & $4.4(2.3)$ & $4.0(1.7)$ & 103 & 137 & 38 & 1.5 & 32 & 1.8 & 1.0 \\
\hline Germany & $2.0(1.3)$ & $1.6(0.8)$ & $4.0(2.2)$ & $3.4(1.4)$ & 103 & 109 & 19 & 1.4 & 33 & 1.9 & 1.1 \\
\hline US & $2.2(1.1)$ & $1.6(0.6)$ & $5.0(2.5)$ & 4.1 (1.6) & 101 & 92 & 19 & 0.9 & 30 & 2.1 & 1.0 \\
\hline Switzerland & $2.4(1.3)$ & $2.2(1.1)$ & $4.9(2.4)$ & $4.6(1.9)$ & 109 & 125 & 38 & 1.5 & 34 & 1.4 & 1.0 \\
\hline Germany & $2.5(2.2)$ & $2.3(2.0)$ & $4.8(1.9)$ & $4.4(1.5)$ & 98 & 146 & 38 & 1.2 & 33 & 2.3 & 1.1 \\
\hline US & $3.9(2.2)$ & $3.4(1.1)$ & $8.5(4.3)$ & $7.5(2.5)$ & 105 & 81 & 14 & 1.0 & 16 & 5.8 & 2.2 \\
\hline US & $4.2(2.0)$ & $3.3(1.2)$ & $8.4(3.7)$ & $7.1(2.3)$ & 113 & 159 & 38 & 1.2 & 34 & 2.0 & 1.0 \\
\hline US & $4.5(2.4)$ & $3.8(1.3)$ & 8.8 (3.3) & $7.7(2.2)$ & 116 & 261 & 18 & 1.1 & 35 & 4.2 & 1.0 \\
\hline US & $4.6(2.9)$ & $3.4(2.6)$ & $9.1(1.7)$ & $7.3(1.4)$ & 120 & 172 & 19 & 1.5 & 32 & 1.0 & 1.0 \\
\hline US & $4.6(2.4)$ & $3.9(1.4)$ & $9.8(4.2)$ & $8.8(2.7)$ & 116 & 114 & 19 & 0.8 & 32 & 1.1 & 1.0 \\
\hline US & $4.7(2.5)$ & $3.8(1.5)$ & $10.4(5.1)$ & $9.0(3.1)$ & 103 & 175 & 19 & 0.9 & 31 & 1.5 & 1.0 \\
\hline US & $4.8(1.7)$ & $3.7(1.0)$ & $11.2(3.9)$ & $9.4(2.1)$ & 118 & 165 & 19 & 1.1 & 30 & 2.0 & 1.0 \\
\hline US & $4.8(3.0)$ & $4.6(2.4)$ & $8.9(3.3)$ & $8.8(2.6)$ & 112 & 123 & 19 & 0.9 & 33 & 3.2 & 1.1 \\
\hline US & $4.9(2.4)$ & $4.0(1.3)$ & $10.7(5.0)$ & $9.3(2.9)$ & 104 & 179 & 19 & 0.9 & 31 & 1.5 & 1.0 \\
\hline US & $4.9(2.5)$ & $5.2(3.0)$ & $11.6(6.0)$ & $11.9(6.4)$ & 107 & 193 & 19 & 1.0 & 31 & 1.5 & 1.0 \\
\hline US & $5.5(3.3)$ & $4.4(1.7)$ & $12.2(5.7)$ & $10.5(3.9)$ & 114 & 157 & 19 & 0.9 & 31 & 1.4 & 1.0 \\
\hline US & $5.8(2.8)$ & $4.7(1.7)$ & $12.6(4.6)$ & $10.8(2.9)$ & 114 & 163 & 38 & 0.8 & 32 & 2.0 & 1.0 \\
\hline US & $6.0(1.9)$ & $5.4(1.3)$ & $13.8(5.1)$ & $12.8(3.8)$ & 112 & 201 & 19 & 0.9 & 29 & 2.2 & 1.1 \\
\hline US & $6.9(3.6)$ & $6.7(3.5)$ & $14.3(2.7)$ & $14.2(2.6)$ & 120 & 187 & 19 & 1.0 & 32 & 3.9 & 1.0 \\
\hline US & $6.9(4.5)$ & $6.8(3.7)$ & $13.3(4.2)$ & $13.3(3.8)$ & 118 & 152 & 18 & 0.9 & 29 & 3.7 & 1.3 \\
\hline US & $7.1(2.9)$ & $7.5(3.7)$ & $15.2(5.4)$ & $15.7(5.4)$ & 120 & 175 & 19 & 0.9 & 31 & 3.1 & 1.1 \\
\hline US & $8.0(6.5)$ & $7.8(5.6)$ & $16.2(9.4)$ & $15.8(6.0)$ & 121 & 174 & 38 & 0.8 & 30 & 1.1 & 1.1 \\
\hline US & $8.2(6.0)$ & $8.2(6.2)$ & $10.0(5.4)$ & $10.0(5.7)$ & 105 & 172 & 12 & 1.0 & 23 & 4.0 & 2.7 \\
\hline US & $9.1(5.5)$ & $7.3(4.4)$ & $9.3(4.3)$ & $8.0(3.4)$ & 109 & 132 & 19 & 0.8 & 37 & 2.8 & 1.1 \\
\hline US & $10.5(1.6)$ & 7.1 (1.9) & $22.7(2.8)$ & $17.1(3.2)$ & 120 & 278 & 14 & 1.0 & 16 & 5.1 & 2.1 \\
\hline US & $11.4(8.2)$ & $9.9(6.3)$ & $18.3(6.5)$ & $16.8(4.4)$ & 112 & 265 & 27 & 1.0 & 21 & 2.9 & 2.2 \\
\hline US & $11.5(4.7)$ & $9.1(4.0)$ & $9.5(3.8)$ & $7.9(3.2)$ & 111 & 277 & 17 & 1.0 & 42 & 4.4 & 1.9 \\
\hline US & $13.4(4.0)$ & $18.3(8.0)$ & $51.5(11.1)$ & $65.9(25.4)$ & 120 & 180 & 19 & 0.2 & 19 & 2.0 & 1.0 \\
\hline US & $15.4(7.3)$ & $12.4(2.7)$ & $13.2(5.8)$ & $10.9(2.2)$ & 109 & 200 & 19 & 1.0 & 39 & 5.0 & 2.0 \\
\hline US & $16.5(7.5)$ & $12.6(3.1)$ & $13.4(5.4)$ & $11.1(2.8)$ & 115 & 199 & 38 & 1.0 & 43 & 2.8 & 2.0 \\
\hline US & $26.2(17.6)$ & $20.0(11.3)$ & $16.9(8.7)$ & $13.8(6.0)$ & 116 & 190 & 38 & 0.8 & 41 & 3.1 & 1.2 \\
\hline US & 29.3 (13.1) & $29.7(7.3)$ & $14.1(4.7)$ & $14.4(2.7)$ & 120 & 161 & 19 & 0.9 & 35 & 4.0 & 4.1 \\
\hline US & $37.4(15.4)$ & $32.7(11.6)$ & $21.3(6.2)$ & $19.4(3.6)$ & 120 & 211 & 19 & 0.8 & 41 & 4.6 & 2.8 \\
\hline $\begin{array}{l}\text { Lowest tenth in } \\
\text { protocols }\end{array}$ & $2.0(1.1)$ & $1.6(0.7)$ & $4.5(2.3)$ & $3.8(1.6)$ & 102 & 113 & 25 & 1.2 & 32 & 1.9 & 1.0 \\
\hline $\begin{array}{l}\text { Highest tenth } \\
\text { in protocols }\end{array}$ & $31.0(15.4$ & $27.5(10.1)$ & $17.4(6.6)$ & $15.9(4.1)$ & 119 & 188 & 26 & 0.8 & 39 & 3.9 & 2.7 \\
\hline
\end{tabular}

likely to reflect country norms. We report effective dose, but the results were similar when limited to volumetric CT dose index or to single CT scans. We do not have a measure of image quality and cannot be sure that institutions with the lowest doses had image quality sufficient for diagnosis; however, each institution determined that their protocols provided adequate diagnostic information for their patients.

Our analyses did not include several technical factors associated with dose (eg, use of iterative reconstruction software), but such software, when used in actual practice, has been shown to have only a modest effect on dose. ${ }^{43}$ The inclusion of these factors would probably further reduce dose variation. The availability of alternative imaging modalities (eg, magnetic resonance imaging) could affect the case mix of patients who undergo CT, and we did not have information on availability of other imaging modalities. Our report on dose variation for a single indication on a single machine model indicates that some variability might be due to how the machines were configured.
Finally, the institutions included in this registry are a convenience sample of institutions that use Radimetrics dose monitoring software. Institutions that invest in dose monitoring software might systematically differ from institutions that do not, although our doses were similar to published accounts by country. We plan to diversify our CT registry, and invite any institution that would like to participate.

\section{Conclusions and policy implications}

CT scanning doses varied widely across included countries. Variation was chiefly driven by how machines were used, rather than by patient or machine manufacturer or model. Optimizing doses to a more consistent standard should be possible both within and between countries by modifying the decisions made by radiology teams in developing CT protocols for patients. Future research should focus on understanding factors that drive institutions, and scientifically comparing different approaches for optimizing doses. 


\section{AUTHOR AFFILIATIONS}

${ }^{1}$ Department of Radiology and Biomedical Imaging Epidemiology and Biostatistics, Obstetrics Gynecology and Reproductive Sciences, Philip R Lee Institute for Health Policy Studies, University of California San Francisco, San Francisco, CA, USA

${ }^{2}$ Department of Radiology and Biomedical Imaging, University of California San Francisco, San Francisco, CA, USA

${ }^{3}$ Department of Demography, University of California Berkeley, Berkeley, CA, USA

${ }^{4}$ Department of Medicine, Division of Cardiology and Department of Radiology, Columbia University Medical Center, New York, NY, USA ${ }^{5}$ Assuta Medical Center, Tel Aviv-Yafo, Israel

${ }^{6}$ Department of Medical Physics, Churchill Hospital, Oxford University Hospitals NHS Foundation Trust, Oxford, UK ${ }^{7}$ Department of Diagnostic and Interventional Radiology, Helios Kliniken Duisburg, Duisburg, Germany

${ }^{8}$ Department of Radiology and Nuclear Medicine, Maastricht University Medical Center, Maastricht, Netherlands

9 Department of Radiology, Icahn School of Medicine at Mount Sinai, New York, NY, USA

${ }^{10}$ Henry Ford Health System, Radiology and Public Health Sciences, Detroit, MI, USA

${ }^{11}$ Department of Radiology, Einstein Healthcare Network, New York, NY, USA

${ }^{12}$ University of California San Diego, San Diego, CA, USA

${ }^{13}$ Cantonal Hospital Aarau, Aarau, Switzerland

${ }^{14}$ Department of Radiology, University California Davis Medical Center, Sacramento, CA, USA

${ }^{15}$ St Luke's International Hospital, Tokyo, Japan

${ }^{16}$ Department of Diagnostic and Interventional Radiology and Neuroradiology, University Hospital Essen, Essen, Germany

${ }^{17}$ Institute of Diagnostic and Interventional Radiology and Neuroradiology, Essen University, Essen, Germany

${ }^{18}$ Department of Public Health Sciences, University of California

Davis School of Medicine, Sacramento, CA, USA

${ }^{19}$ Kaiser Permanente Washington Health Research Institute, Kaiser

Permanente Washington, Seattle, WA, USA

Contributors: RS-B contributed to obtaining funding, performing literature searchers, study design, data collection, data analysis, data interpretation, and writing the manuscript, and is the study guarantor. YW contributed to data analysis, data interpretation, and writing of the manuscript. PC contributed to data collection, data analysis, data interpretation, and writing of the manuscript. RC contributed to data analysis, data interpretation, and writing of the manuscript. AJE contributed to performing literature searches, study design, data analysis, data interpretation, and writing of the manuscript. RG, TRN, and AS contributed to the study design, data collection, data interpretation, and writing of the manuscript. DLM contributed to obtaining funding, study design, data collection, data analysis, data interpretation, and writing of the manuscript. The remaining authors contributed to data collection, data interpretation and writing of the manuscript. The corresponding author attests that all listed authors meet authorship criteria and that no others meeting the criteria have been omitted.

Funding: Funded by the US National Institutes of Health (R01CA181191); Patient-Centered Outcomes Research Institute (CD-1304-7043); Centers for Disease Control and Prevention; and the University of California Office of the President, Center for Health Quality and Innovation; Chris Tachibana edited this manuscript, funded by Kaiser Permanente Washington Health Research Institute. Funders had no role in study design, collection, analysis, interpretation, and reporting of data; or decision to publish.

Competing interests: All authors have completed the ICMJE uniform disclosure form at www.icmje.org/coi_disclosure.pdf and declare: support from the US National Institutes of Health; Patient-Centered Outcomes Research Institute; Centers for Disease Control and Prevention; and the University of California Office of the President, Center for Health Quality and Innovation for the submitted work; RS-B reports grants from the US National Institutes of Health, PatientCentered Outcomes Research Institute, Centers for Disease Control and Prevention, and the University of California Office of the President, is on a scientific advisory board, and has given talks for Bayer Healthcare; BND is on a scientific advisory board and has given talks for Bayer Healthcare; AJE has served as a consultant to GE Healthcare, and Columbia University has received support for other research from Toshiba America Medical Systems; MD reports grants and personal fees from Bayer Healthcare, grants and personal fees from Siemens Healthcare, grants from Philips Healthcare, personal fees from Cook Medical, outside the submitted work; AS reports non-financial support and is on Bayer Healthcare scientific advisory board; JS has given talks for Bayer Healthcare; JEW reports institutional grants from Agfa, Bard, Bayer, GE, Optimed, Philips, Siemens, personal fees (speaker's bureau) from Bayer, Siemens, outside the submitted work; DLM is on an advisory board for Hologic; the remaining authors have nothing to disclose.

Ethical approval: The institutional review boards at the University of California San Francisco (and the collaborating institutions) approved the study or relied on the university's approval.

Data sharing: No additional data currently available.

The lead author affirms that the manuscript is an honest, accurate, and transparent account of the study being reported; that no important aspects of the study have been omitted; and that any discrepancies from the study as planned (and, if relevant, registered) have been explained.

This is an Open Access article distributed in accordance with the Creative Commons Attribution Non Commercial (CC BY-NC 4.0) license, which permits others to distribute, remix, adapt, build upon this work non-commercially, and license their derivative works on different terms, provided the original work is properly cited and the use is noncommercial. See: http://creativecommons.org/licenses/by-nc/4.0/.

1 Smith-Bindman R, Lipson J, Marcus R, et al. Radiation dose associated with common computed tomography examinations and the associated lifetime attributable risk of cancer. Arch Intern Med 2009;169:2078-86

2 Lukasiewicz A, Bhargavan-Chatfield M, Coombs L, et al. Radiation dose index of renal colic protocol CT studies in the United States: report from the American College of Radiology National Radiology Data Registry. Radiology 2014;271:445-51. doi:10.1148/ radiol.14131601

3 European Commission. Diagnostic Reference Levels in Thirty-six European Countries Part 2/2. Publications Office of the European Union, 2014.

4 Parakh A, Euler A, Szucs-Farkas Z, Schindera ST. Transatlantic Comparison of CT Radiation Doses in the Era of Radiation DoseTracking Software. AJR Am J Roentgenol 2017;209:1302-7. doi:10.2214/AIR.17.18087

5 Radiation. International Agency for Research on Cancer (IARC). Monogr Eval Carcinog Risks Hum 2012;100:7-303.

6 Berrington de González A, Darby S. Risk of cancer from diagnostic X-rays: estimates for the UK and 14 other countries. Lancet 2004;363:345-51. doi:10.1016/S0140-6736(04)15433-0

7 Board of Radiation Effects Research Division on Earth and Life Sciences National Research Council of the National Academies. Health Risks from Exposure to Low Levels of lonizing Radiation: BEIR VII Phase 2 Washington. The National Academies Press, 2006.

8 Richardson DB, Cardis E, Daniels RD, et al. Risk of cancer from occupational exposure to ionising radiation: retrospective cohort study of workers in France, the United Kingdom, and the United States (INWORKS) [correction in: BMJ 2015;351:h6634] BMJ 2015;351:h5359. doi:10.1136/bmj.h5359

9 Cardis E, Vrijheid M, Blettner M, et al. Risk of cancer after low doses of ionising radiation: retrospective cohort study in 15 countries. BMJ 2005;331:77. doi:10.1136/ bmj.38499.599861.E0

10 Davies HE, Wathen CG, Gleeson FV. The risks of radiation exposure related to diagnostic imaging and how to minimise them. BM/ 2011;342:d947. doi:10.1136/bmj.d947

11 Mathews JD, Forsythe AV, Brady Z, et al. Cancer risk in 680,000 people exposed to computed tomography scans in childhood or adolescence: data linkage study of 11 million Australians. BMJ 2013;346:f2360. doi:10.1136/bmj.f2360

12 Sodickson A. CT radiation risks coming into clearer focus. BMJ 2013:346:f3102 doi:10.1136/bmj.f3102

13 Pearce MS, Salotti JA, Little MP, et al. Radiation exposure from CT scans in childhood and subsequent risk of leukaemia and brain tumours: a retrospective cohort study. Lancet 2012;380:499-505. doi:10.1016/S0140-6736(12)60815-0

14 Martin DR, Semelka RC. Health effects of ionising radiation from diagnostic CT. Lancet 2006;367:1712-4. doi:10.1016/S01406736(06)68748-5

15 Catalano C, Francone M, Ascarelli A, Mangia M, Iacucci I, Passariello R. Optimizing radiation dose and image quality. Eur Radiol 2007;17(Suppl 6):F26-32. doi:10.1007/s10406007-0225-6

16 Trattner S, Pearson GDN, Chin C, et al. Standardization and optimization of CT protocols to achieve low dose. J Am Coll Radiol 2014;11:271-8. doi:10.1016/j.jacr.2013.10.016

17 Goske MJ, Strauss KJ, Coombs LP, et al. Diagnostic reference ranges for pediatric abdominal CT. Radiology 2013;268:208-18. doi:10.1148/radiol.13120730 
18 International Council on Radiological Protection (ICRP). Diagnostic Reference Levels in Medical Imaging, ICRP Publication 135. Ann ICRP 46(1). Ann ICRP 2017.

19 Rosenstein M. Diagnostic reference levels for medical exposure of patients: ICRP guidance and related ICRU quantities. Health Phys 2008;95:528-34. doi:10.1097/01. HP.0000326331.35187.63

20 European Society of Radiology. Eurosafe Imaging, EUCLID (European Study on Clinical Diagnostic Reference Levels for X-ray Medical Imaging) 2007. www.eurosafeimaging.org/euclid.

21 Ormsby EL, Pavlik EJ, van Nagell JR. Ultrasound follow up of an adnexal mass has the potential to save lives. Am J Obstet Gynecol 2015;213:657-61.

22 Christner JA, Kofler JM, McCollough CH. Estimating effective dose for CT using dose-length product compared with using organ doses: consequences of adopting International Commission on Radiological Protection publication 103 or dual-energy scanning. AJR Am J Roentgenol 2010;194:881-9. doi:10.2214/ AJR.09.3462

23 American Association of Physicists in Medicine. American Association of Physicists in Medicine Report No 96. The Measurement, reporting and management of radiation dose in CT, Report of AAPM Task group 23 of the Diagnostic Imaging Council CT Committee. American Association of Physicists in Medicine, 2008.

24 Japan Network for Research and Information on Medical Exposures (J-RIME) and the Japan Medical Imaging and Radiological Systems Industries Association and National Institute of Radiological Sciences. Diagnostic Reference Levels Based on Latest Surveys in Japan Japan DRLs 2015-2015. http://www.iomp.org/sites/default/files/ drlhoukokusyoeng.pdf.

25 Kanal KM, Butler PF, Sengupta D, Bhargavan-Chatfield M, Coombs LP, Morin RL. U.S. Diagnostic Reference Levels and Achievable Doses for 10 Adult CT Examinations. Radiology 2017;284:120-33. doi:10.1148/radiol.2017161911

26 van der Molen AJ, Schilham A, Stoop P, Prokop M Geleijns J. A national survey on radiation dose in CT in The Netherlands. Insights Imaging 2013;4:383-90. doi:10.1007/ s13244-013-0253-9

27 Treier R, Aroua A, Verdun FR, Samara E, Stuessi A Trueb PR. Patient doses in CT examinations in Switzerland: implementation of national diagnostic reference levels. Radiat Prot Dosimetry 2010;142:244-54. doi:10.1093/rpd/ncq279

28 Public Health England. Diagnostic Radiology: National Diagnostic reference levels. NDRLS, 2016.

29 Dose Index Registry - American College of Radiology. American College of Radiology. https://www.acr.org/Quality-Safety/NationalRadiology-Data-Registry/Dose-Index-Registry. 2015

30 Joint Commission on Hopsital Accreditation. Diagnostic imaging requirements $2015 \mathrm{https}$ ://www.jointcommission.org/assets/1/18/ AHC_DiaglmagingRpt_MK_20150806.pdf.
31 European Society of Radiology (ESR). Summary of the European Directive 2013/59/Euratom: essentials for health professionals in radiology. Insights Imaging 2015;6:411-7. doi:10.1007/s13244015-0410-4

32 European Commission. Radiation Protection 109. Guidance on diagnostic reference levels (DRLs) for medical exposures. Office for Official Publications of the European Communities, 1999.

33 European Union. Council Directive 97/43/Euratom of 30 June 1997 on health protection of individuals against the dangers of ionizing radiation in relation to medical exposure, and repealing Directive 84/466/Euratom. 1997.

34 European Union. Council Directive 2013/59/Euratom laying down basic safety standards for protection against the dangers arising from exposure to ionising radiation, and repealing Directives 89/618/ Euratom, 90/641/Euratom, 96/29/Euratom, 97/43/Euratom and 2003/122/Euratom. 2013.

35 Valentin J, International Commission on Radiation Protection. Managing patient dose in multi-detector computed tomography(MDCT). ICRP Publication 102. Ann ICRP 2007;37:1-79, iii.

36 Committee on Medical Apects of Radiation in the Environment (COMPARE). Sixteenth Report. Radiation dose issues resulting fron the use of CT in the UK: Public Health England, 2014

37 US Food and Drug Administration. FDA White Paper: Initiative to Reduce Unnecessary Radiation Exposure from Medical Imaging 2010. https://www.fda.gov/Radiation-EmittingProducts/ RadiationSafety/RadiationDoseReduction/ucm199994.htm.

38 Smith-Bindman R. Is computed tomography safe?N Engl J Med 2010;363:1-4

39 Loose RWR. Clinical diagnostic reference levels: from concept to impact in clinical practice. Abstract A143, European Congress of Radiology 2017, A-143. European Congress of Radiology 2017.

40 European Commission. Medical Protection No 180. Medical Radiation Exposure of the European Population. Part 1/2. Luxenbourg Publications Office of the European Union, 2014

41 Smith-Bindman R, Chu P, Wang Y, Chung R, Einstein A, Miglioretti DL. An international randomized controlled trial of two interventions for reducing doses for computed tomography through audit feedback and sharing best practices. European Congress of Radiology, European Society of Radiology, Vienna, Austria, March 2018.

42 Demb J, Chu P, Nelson T, et al. Optimizing Radiation Doses for Computed Tomography Across Institutions: Dose Auditing and Best Practices. JAMA Intern Med 2017:177:810-7. 10.1001/ jamainternmed.2017.0445

43 Smith-Bindman R, Wang Y, Yellen-Nelson TR, et al. Predictors of CT Radiation Dose and Their Effect on Patient Care: A Comprehensive Analysis Using Automated Data. Radiology 2017;282:182-93. doi:10.1148/radiol.2016151391

Web appendix: Supplementary materials 